\title{
0599 INHIBITORY CONTROL AND CHILDREN'S RISK FOR DOG BITES
}

\author{
A L Davis*, D C Schwebel, B A Morrongiello, J Stewart, M Bell, E E \\ Oneal Correspondence: University of Alabama at Birmingham, 3067 Tyler Crest Cir. \\ Hoover, AL 35226, USA

\subsection{6/ip.2010.029215.599}

Introduction Approximately 400000 US children seek medical attention for dog bites annually (CDC, 2008). A dozen die. Inhibitory control, the capacity to plan and suppress inappropriate approach responses under instruction or in novel situations (Rothbart et al, 2001), is linked to broad child injury risk (Schwebel \& Plumert, 1999), but is poorly understood as a risk factor for pediatric dog bites.

Method 82 children (mean 4.84 years; SD=0.91, 46\% male) were recruited from Birmingham, USA and Guelph, Canada. All lived in homes with 1-3 dogs. Parents completed the inhibitory control scale of the Children's behaviour questionnaire (Rothbart et al, 1994) and items concerning children's history with dogs.

Results Inhibitory control correlated to parent-report of children's history of almost being bitten by a dog, $r=-0.27$; uninhibited children were more likely to have almost experienced dog bites. Inhibitory control also related to parent-report of children's negative experiences with dogs that resulted in crying, $r=-0.29$, (uninhibited children more likely to have 


\section{IP Safety 2010 abstracts}

had negative incidents); of children playing rough with dogs, $\mathrm{r}=-0.31$ (uninhibited children playing rough with dogs); and of parent concern that children's behaviour will anger their dog, $\mathrm{r}=-0.25$ (parents of uninhibited children more concerned).

Implications Current dog bite prevention strategies focus on dog control and owner education (eg, leash laws, animal training). These strategies help, but identification of child specific risk factors, such as inhibitory control, could aid development of other dog-bite prevention programs. 